\title{
When Will the Pandemic End? Suggestions for US Communities to Manage Well-Being in the Face of COVID-19
}

\author{
Clinton Bliss $^{1} \cdot$ Laura Musikanski $^{2}$ (D) $\cdot$ Rhonda Phillips $^{3} \cdot$ Larry Davidson $^{4}$
}

Received: 22 July 2020 / Accepted: 13 August 2020/Published online: 24 August 2020

(C) Springer Nature Switzerland AG 2020

\begin{abstract}
With COVID-19 largely spread through communities, and the lack of a national strategy to manage the spread and impact of COVID-19 into communities in the United States (US), community well-being is at risk. Without a vaccine, the COVID-19 pandemic is likely to continue for years and cause millions of deaths, primarily among the elderly and the chronically ill. A vaccine for the COVID-19 could safeguard community well-being, but cannot be counted upon at this point. We believe it is imperative for communities to form and implement strategies to manage the spread and impacts of COVID-19 and that understanding the overall death rate and for young people (ages 15-35) as well at the length of the pandemic in important to planning. We calculate an overall death rate at $1 / 116$, a death rate of $1 / 3944$ for young adults, and that at the current rate of infection the pandemic will last for just under 10 years or possibly indefinitely as there is no guarantee that immunity will last. Measures such as social distancing and self-quarantining are effective but have detrimental economic, educational, social and psychological impacts. Community leaders and organizers need to understand that a growing number of young people will likely not adhere to social distancing and self-quarantining indefinitely. We recommend that communities form and implement plans to managing the spread and impact of COVID-19 within a specific time frame and urge young people to adhere to measures to stop the spread for the specific time frame. Community plans should be based on a community development (CD) approach and should entail inclusive and participatory decision-making process that engaged young people. Communities should use this time to transitioning to a well-beingbased local economy and implement interventions that allow for human interaction such as negative pressure ventilation and filtration of air in indoor spaces, availability of universal testing, contract tracing and the widespread use of personal powered air purifying respirators (PAPRs).
\end{abstract}

Keywords COVID-19 · Community well-being $\cdot$ Pandemic

Laura Musikanski

laura@happycounts.org

Extended author information available on the last page of the article 


\section{Introduction}

With COVID-19 largely spread through communities, United States (US) communities, from small rural towns to large cities, face a quandary. Severe acute respiratory syndrome (SARS)-CoV-2 is a virus. Coronavirus (COVID)-19 is the illness that arises from that virus. In this commentary, we use the term COVID-19 to refer to both. While some nations have made concerted efforts to manage the spread of the virus in communities (Bremmer 2020; Gibney 2020), communities in the US are left without guidance at a national level and are at risk of long-term damage to their well-being (United Nations 2020). This commentary is aimed at addressing the core issues in the management by communities of the COVID-19 pandemic.

We believe effective management begins with understanding a range of potential long-term impacts of COVID-19 on the population of communities. In this commentary, we predict the length of the pandemic and the potential cost in human lives, provide an explanation of the role of community development (CD) in managing the spread of COVID-19 and make recommendations for protecting community wellbeing.

\section{Predicting the Length of the Pandemic}

We base our forecast of the length of the COVID-19 pandemic on data for death rates. Optimally, entire community populations would have been tested at regular intervals, and we all would have access to the data we need to understand the current and future impacts. This is not the case. We understand that the amount of information about the actual number of people infected with COVID-19 in most communities in the US is scant. However, New York City is an exception, and so we use data from New York City's experience to deepen our understanding. We used the most current data we could access. We assumed that proportional descriptions of data did not change significantly over time, and so have used proportional descriptions derived from a data set in one time for other time frames. We also assumed that all age groups in New York City were equally exposed to COVID-19.

\section{Overall Death Rates in the US from COVID-19}

In 2019, the population of New York City was about 8.3 million people (United States Census Bureau n.d.-a). The growth rate is $0.03 \%$ (New York City Department of City Planning n.d.), yielding a population of 8.3 million people in 2020. On April 23, 2020, $21 \%$ of New York City residents had been infected and were immune (Goodman and Rothfeld 2020). Thus, about 1.74 million New York City residents had tested positive for immunity to COVID-19 on April 23. On April 24, 2020 there were just over 15,000 cumulative deaths attributed to COVID-19 in New York City (City of New York n.d.; Li 2020; Torres 2020). Thus, the death rate was $0.86 \%$, or one out of every 116 people infected. These findings are similar to those of Verity et al. (2020), who found an overall death rate of $0.66 \%$. 
In 2019, the population of the US was 330 million (United States Census Bureau n.d.-b). The average population growth rate in the US between 2010 and 2018 was $0.69 \%$ (The World Bank 2020), however the growth rate in 2018 was $0.52 \%$ due to a decline in immigration and childbirth seen by Pew Research Center (Cilluffo and Cohn 2019) and so we assumed a growth rate of $0.52 \%$ between 2019 and 2020, for a US population of 332 million people in 2020 . With a death rate of $0.88 \%$, we extrapolate that if every person in the US were to become infected with COVID-19, there would be 2.86 million deaths in the US due to COVID-19. Our extrapolation is based on an assumption that health care will be accessible at the same level that it was in New York City between the onset of the pandemic and April 24, 2020. It is also based on an assumption of one round of infection, and does not contemplate re-infection or the possible increase or decrease in death rates upon re-infection.

The number of deaths could be curtailed if a vaccine were to be found. A vaccine within the next year is not inconceivable (Kakodhar et al. 2020), but it could be years away (Ghaebi et al. 2020). Variations of coronaviruses have plagued humans for a long time and yet no vaccine exists for any other coronavirus (Sample 2020). More recently, SARS epidemic in 2002-2003 (World Health Organization 2020) and the middle east respiratory syndrome (MERS) epidemic in 2012 (Centers for Diseases Control and Prevention CDC, n.d.-b) are both caused by corona viruses that wreaked havoc and yet to date, there is no vaccine for either. Hepatitis $\mathrm{C}$, human immunodeficiency virus (HIV), and ebola are other serious diseases for which there is yet to be a vaccine (McNeil 2018). Thus, we recommend that communities assume that a vaccine may not be available in the near future and plan with an assumption of a death rate of $0.86 \%$, even when there is adequate health care available.

\section{Death Rates for Young Adults}

We define young adults as people between the ages of 15 and 34. In 2019 in the US, $27 \%$ of the population was between 15 and 34 (United States (US) Census Bureau, 2019). On June 24, 2020, the CDC (2020b) reported the cumulative number of deaths in the US attributed to COVID-19 was 107,997, with 864 of the deceased having been between the ages 15-34. If the death rate for all age groups were indiscriminate, we could predict a death toll for young adults of 29,159, or 27\% of 107,997 (Centers for Diseases Control and Prevention (CDC) n.d.-b). Based on the discrepancy, we calculate a decrease in the actual risk of death to young adults based on the proportion of young adults who actually died from COVID-19 divided by the expected number of young adults' deaths if COVID-19 were an indiscriminate killer. This comes to 3\% less likelihood of death from COVID-19 for young adults than the general population, or $1 / 34$ (864 divided by 29,159 ). Following the mathematical rules of compound probability, we take the absolute risk of death for the entire population at 1/116 multiplied by the relative risk of death for the population of young adults ages 15-34 at 1/34 to arrive at the absolute risk for death for this specific population at $1 / 3944$ or $0.025 \%$ chance of dying.

We make the assumption that the death rate for the entire US population will be the same as for New York City (1/116). Thus, we calculate the death rate for young adults by multiplying $1 / 116$ and $1 / 34$ to get a death rate of $1 / 3944$ or $0.025 \%$. United States (US) Census Bureau (2019) data for 2019 indicates that this age group represents $27 \%$ 
of the US population, or 89.1 million. The World Bank (2020) indicates the average US population growth rate was $0.522 \%$ for 2019 , thus we arrive at a population of 89.6 million young adults in the US in 2020 . Multiplying 89.6 million by $1 / 3944$, we project a total of 22,718 deaths in young adults from the pandemic, in contrast to 2.86 million deaths in the general population.

\section{Forecasting the Duration of the Pandemic}

Pandemics end when herd immunity is achieved. Herd immunity is "when a large portion of a community (the herd) becomes immune to a disease, making the spread of disease from person to person unlikely. As a result, the whole community becomes protected — not just those who are immune" (Mayo Clinic 2020). The size of the herd that must be immune is directly proportional to how contagious a disease is (Mayo Clinic 2020). We are still learning about how contagious COVID-19 is (Sache et al. 2020). Moreover, we do not know how long immunity lasts, the impact on future infections of immunity and many other factors (Joseph 2020). We do know that COVID-19 is more deadly for those with an underlying medical condition (Witters and Agraway 2020). In the US, $60 \%$ of adults have an underlying health condition (Centers for Diseases Control and Prevention (CDC) n.d.-a) and while we project 2.86 million deaths, Witters and Agraway (2020) suggest the total deaths could come to 11 million. Because there is so much unknown and COVID-19 is more dangerous for certain segments of the population, for this commentary, we take a conservative approach and assume $95 \%$ of the population must be immune to calculate the time it will take to achieve herd immunity to COVID-19 in the US.

On July 10, 2020, the average deaths per day attributed to COVID-19 in the US was 785, derived from a total death toll between February 2, 2020 and July 4, 2020 (152 days) at 119,318 deaths (Centers for Diseases Control and Prevention (CDC) 2020c). We use this number with the understanding that it is changing every day. Based on our calculations for New York City survival versus infection rate, we estimate that for every one person who died, 115 other people were infected and did not die. Thus, with a death rate at 785 a day, a total of 91,060 people are infected a day, or 2.732 million a month.

Table 1 shows the number of years that it would take for each person in the US population to get infected depending on the rate of spread. These projections show that with a constant daily infection rate of 91,060 new cases per day, it will take just under 10 years for the $95 \%$ of the US population to become infected, and we can expect a death toll of 2.72 million deaths. If the infection rate is exponential, depending on the exponent with a range between doubling to increasing by $1.1 \%$, it will take between about 1.4 years to 4.15 years until $95 \%$ of the US population is infected.

We raise important caveats to our projections. Re-infection rates and the death rates from re-infection of COVID-19 are unknown. The common cold, a form of coronavirus, returns on a regular basis to many communities, and so could COVID-19. A study of the SARS epidemic in 2003 showed that immunity decreased significantly by 3 years after infection ( $\mathrm{Wu}$ et al. 2007). This could be the case for COVID-19 - we do not know. Thus, while we project an end to the pandemic with $95 \%$ immunity in a certain 
Table 1 Expected Duration of the Pandemic

Approximate Years to Herd Immunity

Linear growth, each day the same amount of infections

Exponential growth, infections double monthly

Exponential growth, infections grow at rate of 1.5 monthly

Exponential growth, infections grow at rate of 1.1 monthly
9.6

1.4

2.4

4.15

Source: United States Census Bureau (n.d.-b). QuickFacts United States; Centers for Disease Control and Prevention 2020., July 10)*. Daily updates of totals by week and state. *Online Resource updated regularly, hence date changes regularly

number of years, that immunity could dissipate over time in a community, and the pandemic could pick up again within and across communities.

\section{The Role of Youth in Death Rates, It's Implications and our Recommendation}

One week after the first day of the summer of 2020, the Washington Post ran a headline: "Young people urged to take virus more seriously as pandemic worsens in the U.S." (Gowen et al. 2020, p.1). The advent of summer was not the first time that young people had ignored precautionary measures for stemming the spread of COVID19. Moore et al. (2020) found that three weeks into March of 2020, young adults were inclined to ignore recommendations to socially distance and self-quarantine. Prior to the publication of Moore et al. (2020) study, young people demonstrated their findings during the spring break of 2020 in Florida, when droves of young adults congregated at close quarters in bars, on the beaches and at theme parks (Mazzi and Robles 2020).

We believe that the relatively low death rate for young adults influences their decisions and is a disincentive to observe social distancing and self-quarantine and other behaviors. Historically, after auto accidents (Chang 2008), suicide is the second leading cause of death among young adults (Suicide Prevention Resource n.d.). In 2010, 26,914 young adults died from car accidents, 10,335 thousand suicide and 8936 from homicide (Centers for Diseases Control and Prevention (CDC) 2020a). Our forecasted death toll among young adults of 22,718 from COVID-19 over the course of the pandemic comes to between 2366 to 16,227 per year, depending on the length of the pandemic. Based on an actual death toll to young adults of 864 between February 2, 2020 and June 24, 2020 (Centers for Diseases Control and Prevention (CDC) 2020c), one could forecast 2075 deaths a year. This means that the chance of dying from COVID-19 is less than the chance of dying from a car accident, suicide or homicide based on the current death toll from COVID-19.

We believe that young adults will be increasingly less inclined to participate in behaviors that slow the spread of COVID-19 as time goes by because they are less likely to die. Thus, we can expect the spread to increase exponentially, and for communities to become increasingly risky places for many of their members in absence of community-driven approaches to manage the spread. In our view there is a great need to realistically manage the spread of COVID-19 into communities with the reality of young adults not adhering to behaviors that stop the spread of COVID-19. It has been proven that self-quarantining and social distancing slow the spread of COVID-19 
(Irfan 2020), but it is unrealistic to expect young people to continue these practices indefinitely. These practices are also potentially detrimental to their well-being. We are concerned about the impact that social distancing and self-quarantining will have on young adults. Social distancing takes a toll on individual and community well-being (Novotney 2019), and may take a particularly high toll on young adults. Vitelli (2020) suggests that suicides are likely to increase significantly due to social distancing. Reger et al. (2020) point to the loss of resources such as community and religious support, mental health treatment for many people when self-quarantined, and the increased risk of suicide due to this loss.

We do believe that young people will adhere to measures to slow the spread of COVID-19 if they are time bound and there is a clear reason. Therefore we recommend that communities, particularly local governments, formulate a plan to manage the spread and impacts of COVID-19 within a specific time frame such as three to six months, and ask young adults to adhere to social distancing and self-quarantining for that specific time period, with the promise that a management plan will be put in place. We suggest a $\mathrm{CD}$ framework for the formation of that plan, and recommend a few specific interventions.

\section{A Community Development Framework}

Without a consistent national framework in place to manage COVID-19 in the US, we believe that it is imperative for communities to be involved in the development of rules, guidelines and practices that balance individual freedoms and the collective good. Thus, we feel a CD framework is called for at this time. A CD approach allows community leaders and members to better understand their individual and collective health, economic, social, ecological and psychological needs so that they can respond appropriately.

The supporting foundations of CD practice and approaches are keenly appropriate during a time of crisis. $\mathrm{CD}$ approaches aim at making situations better in communities for residents and address the needs and characteristics of a community. CD is a social movement for improving the collective:

"It is concerned with creating better lives globally and ensuring that human beings can become agents of their own destinies. It operates on the basis of a commitment to social justice, social equality and the principles of universal human rights....It is underpinned by a strong emphasis on meaningful community participation and collaboration" (Kenny et al. 2017: xxiv).

The pandemic has exposed underlying social injustices in the US (Dorn et al. 2020), and $\mathrm{CD}$ is needed more than ever to help mitigate deleterious impacts on communities. As CD practice varies widely from place to place, we encourage consideration of some of these practices for addressing issues as well as incorporating effective responses to the pandemic. CD builds a community's capacity to take action (also referred to as social capital). Communities take action by mobilizing resources for community improvement with participatory, inclusive processes and create desired results such as increased standards of living, better social connections and improved community well-being (Phillips and Pittman 2015). 
Interventions to manage the spread of COVID-19 in US states have been variable, with a spectrum ranging from strict lock-downs to stop the spread, to laissez-faire pursuance of herd immunity. In many states, policy-makers have encouraged people to adopt hygiene habits, from self-quarantining to wearing masks, that have proven to slow the spread of COVID-19 (Hsiang et al. 2020; Irfan 2020; Flaxman et al. 2020).

We feel it would be very helpful to encourage more participatory, inclusive decisionmaking by local governments and community-based organizations and to move to governance where those impacted are able to have a voice in the policies and actions being taken. CD processes can aid in addressing critical issues in this unprecedented time, and can also provide ways to assess and gauge effectiveness of responses and actions taken. $\mathrm{CD}$ is a way to involve young adults at the community level to become vested and engaged in the continuing health of the places they call home. We believe youth-led initiatives to encourage safe, responsible protocols can be very effective.

\section{The Local Economy and our Recommendation}

The damage to communities' economy from COVID-19 is beyond the scope of this commentary, but we believe it will be significant and lasting. Unemployment has lasting negative impacts on people's well-being, particularly working age males (Clark et al. 2018) and recessions have lasting negative impacts on community wellbeing. Decisions and actions can be taken to address challenges at the local level. Local communities that identify, understand, assess and devise responses impact community members' ability to thrive (Musikanski et al. 2019). Given the immediacy of critical impacts on local economies of the pandemic, it is imperative that communities respond with feasible and effective plans and actions to help offset losses to local economic health which in turn impacts social and physical health of residents.

We recommend that as part of their managing for the impacts of COVID-19, communities re-organize their economic plans, goals and metrics from financial to well-being based so that communities and individuals define success based on their happiness, community well-being and ecological sustainability rather than financial wealth and income. We point to The Happiness Policy Handbook (2019) which offers steps, tools and resources for such as re-organization. This handbook is written for community members who want to engage their local governments and residents in planning for policy change to support well-being; it includes examples of how to develop proclamations, policies, forums and other participatory methods for achieving well-being (Musikanski et al. 2019).

\section{Community Indicators}

Community indicators represent tools for helping areas assess progress towards goals and while indicators are often used for periodic evaluation, in the time of Covid-19 they could be adjusted to serve purposes of gauging needs and subsequent actions or changes in policies. We recommend using subjective well-being indicators to understand how a community perceived itself to be suffering and flourishing before and during the planning process, such as those in The Happiness Policy Handbook (Musikanski et al. 2019). We also recommend the use of objective indicators to get a balanced picture of the community and guide balanced policies and actions. Phillips 
(2015) recommends the following objective indicators for use by communities to foster well-being based local economy:

- "Economic Indicators: economic diversity (which sectors account for the majority of the economic activity); quality of jobs (in relation to cost of living and skills of the area's residents); jobs/housing balance (number of jobs in relation to housing units and cost of housing); quality of jobs (wages in relation to livable wages and cost of living in community); and types of innovative/alternative enterprises (green/ sustainable or particular sectors that are regarded as socially impactful).

- Socially Responsive Business Indicators: business reinvestment in community; percent businesses majority locally owned versus absentee ownership (including formula retail stores versus locally owned, for example); types of giving and community support; and ownership structures; level and type of activities in sustainability/socially responsiveness (corporate social responsibility and related).

- Social Enterprise Indicators: numbers and types of nonprofit organizations; numbers and types of alternative structure organizations (for benefit corporations, cooperatives, worker-owned organizations, etc.); and longevity and generation of social enterprise organizations (to gauge local environment of support).

- Community Development Indicators: level and type of participation by organizations in civic society; interface with residents (for example, shared facilities, public space, activities and opportunities for interaction); strength of response to issues facing society (level and pervasiveness of major issues in the community whether environmental, social, economic or a combination); and availability of products and services generated in the local area (types including green/sustainable such as local food, arts and cultural products and services).

- Supporting Policy Indicators: policies in place supporting locally focused enterprises and businesses; level and type of support for infrastructure, programs and activities; and responses to issues impacting the ability to foster a locally focused economy" (pp. 29-30).

These indicators could be adjusted or revised to reflect the immediate needs of local economies. They can be used within a community well-being focused framework to assess where attention is needed most and so prioritize allocation of resources and action.

\section{Immediate Interventions to Manage COVID-19 Impacts on Community Well-Being}

We believe that CD will lead to interventions to manage COVID-19 that fit the needs and circumstances of a community. However, in the meantime, we recommend immediate interventions based on our own knowledge and understanding of communities, community well-being and factors impacting the spread of COVID-19. We do not posit that our suggestions are conclusive or technically proven interventions that will slow the spread of COVID-19 and safeguard 
community well-being. We do hope that our suggestions will contribute to communities' capacity to manage their well-being in the face of COVID-19 and will spark researchers, community organizers and entrepreneurs.

\section{Powered Air Purifying Respirators (PAPRs)}

We recommend the use of personal powered air purifying respirators (PAPRs) in place of face masks immediately for elders and others at higher risk, and potentially for all people in the near term. PAPRs are a helmet that goes over the head with a tube attached that provides filtered air continuously through a battery powered blower. PAPRs provide superior protection compared to cloth masks, N95 masks, and surgical masks (CDC, 2020b). They are used in health care settings to prevent COVID-19 exposure to health care workers who are caring for patients who are COVID-19 positive. PAPRs would allow people to get closer than $6 \mathrm{ft}$ apart, allowing people to circulate in society, hug their friends and extended family, and otherwise participate in community activities. We do not delve into the risk of suicide for older people in this commentary but believe it is significant in the face of continued self-quarantining, and feel that PAPRs could help alleviate the threat of increased suicide rates among elders and those with health conditions.

One problem with PAPRs is that they provide one way protection. (It is also necessary for people who use PAPRs to practice good hygiene with regard to their hands and other body parts, as PAPRs do not provide protection from the neck down.) However, we feel PAPRs are a good solution, particularly for older people with a health condition (Fig. 1).

\section{Negative Pressure Ventilation and Improved Filtration of Air}

We recommend research and development in the application of negative pressure ventilation and improved filtration of air in classrooms, child care centers and other places where children and young adults congregate, as well as in nursing homes, restaurants, community centers, churches and spiritual centers, sports arenas, and other places where people congregate. Negative pressure ventilation of rooms is one of the strategies employed in respiratory isolation rooms in hospitals to prevent exposure and control the spread of COVID-19. Negative pressure ventilation pulls air from a room and so makes spread of virus less likely. Nearly every home has this kind of technology in their bathroom or kitchen, where air is pulled out through an overhead fan to rid a room of smoke or odors. Adapting and improving indoor ventilation could entail directing air through a HEPA filter or directly out into the environment and could entail energy efficient heat transfer systems.

\section{Greater Access to and Use of Virtual Meeting Software, Hardware and Connectivity}

Self-quarantining brought on a surge in the use of virtual meeting technology by all ages in a wide range of uses. However, some segments of populations are less prepared or have less access to virtual meetings than others. We recommend that communities work to ensure all people have easy access to virtual meeting software, the hardware necessary to use it as well as internet connectivity. This would include building 


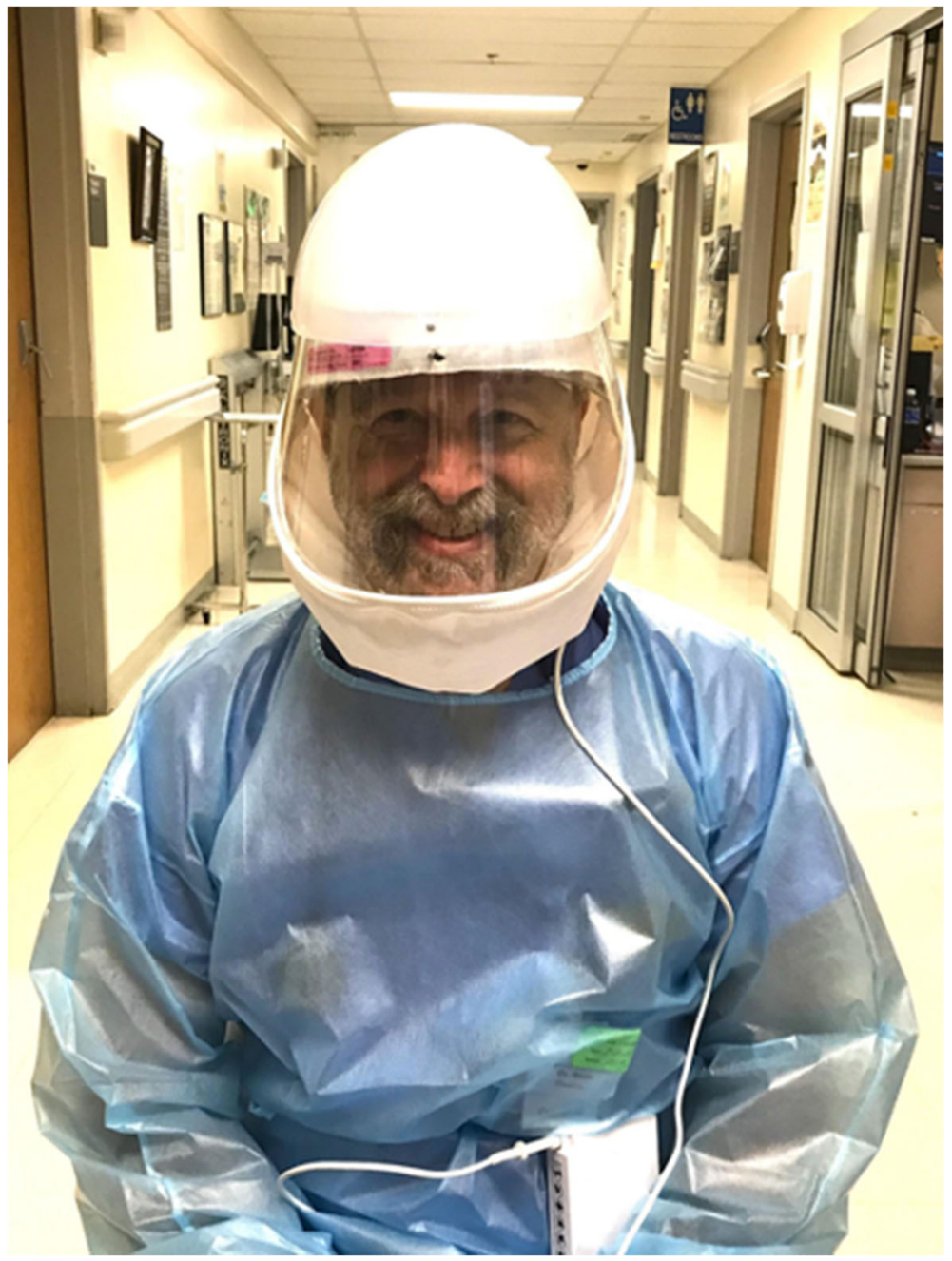

Fig. 1 One of the Authors, an Emergency Doctor, in a PAPR mask

capacity for those who do not have proficiency in virtual meeting technology. In our experience, some communities have begun to set up online connections for alerting where help is needed most and bring in tools common to CD and planning, such as geographic information system technologies.

\section{Availability of Simple, Quick, Inexpensive and Accurate COVID-19 Testing}

We feel that availability of simple, quick, inexpensive and accurate testing for both infection with the COVID-19 virus and immunity should be a high priority for communities, as it will enable communities and individuals to manage the spread. COVID-19 testing comes in two forms. One form tells if someone is infected and the other if they have antibodies. Turnaround time for testing for COVID-19 is forty-five 
minutes at the time of writing this commentary (Biomériex n.d.). One of the authors of this commentary, an emergency room doctor, notes that this is a dramatic improvement, when the testing turnaround was three days less than three months ago. As demand for both types of tests grow, cost should decrease and the speed, accuracy, and simplicity of testing increase. Tests should be available for a cost that is not prohibitive to anyone, regardless of economic status, similar to the cost of soap. They should be extremely easy to access and administer.

\section{Contact Tracing Apps with User Control of Data}

Contract tracing apps are downloaded by cell phone or other device owners, also called users. In our view, there is a need for contact tracing apps that allow users to manage the use of their data and to choose whether or not governments or businesses will have access to their data. Contract tracing apps gather data for where the user has been over time, and who the user has been in proximity with for more than a certain amount of time when other users also have downloaded the app. If one user becomes infected, that user can trigger the app to anonymously notify other users that they have been exposed. Contact tracing apps are only as good as the proportion of people in a community who uses them. If everyone in a community uses them, then when one user gets infected, and the contact tracing app is accurate, all who may have been exposed in the community are notified. Contact tracing apps are compulsory in some areas, such as Beijing (Agency France-Press 2020) and are being used to limit people's movement (Servick 2020) by some governments, which may hinder their uptake in communities in the US. This is one reason we believe that the use and management of contact tracing apps should be based on CD approaches.

\section{Conclusion}

A vaccine for the COVID-19 would be the best defense in this pandemic, but may be years away, and cannot be relied upon as a guarantee. Without a vaccine, the COVID19 pandemic is likely to continue for years and cause millions of deaths, primarily among the elderly and the chronically ill. We calculate the overall death rate at 1/116 and the death rate at 1/3944 for young adults (15-35 years old). The risk of death to young people from COVID-19 is much less than for auto accidents, homicide or suicide. We estimate that at the current rate of infection the pandemic will last for just under 10 years or possibly indefinitely as there is no guarantee that immunity will last. Some young adults are not adhering to measures such as self-quarantining and social distancing and so act as vectors in the spread of the virus, and need to be encouraged to continue with social distancing and self-quarantining but not indefinitely. Social distancing, while remarkably effective, has many detrimental effects on our economy, our educational systems, and our mental health.

Communities need to understand the reality of the situation by which a growing number of young people will likely not adhere to social distancing and selfquarantining indefinitely. We recommend that community leaders ask young people to practice self-quarantining and social distancing for a specific time frame and 
withing that time frame both formulate and commence implementing plans for managing the spread and impact of COVID-19. These plans and interventions should be based on a CD approach and should include young people in an inclusive and participatory decision-making process. It should include a transitioning to a well-being-based local economy.

When we protect individual well-being, then overall community well-being will improve as well and social connections can continue. We need to explore other mechanisms of personal protection that allow a greater range of human interaction. Interventions we recommend include negative pressure ventilation and filtration of air in indoor spaces, availability of universal testing and contract tracing. Most promising at present is a wider availability and use of PAPRs for the elderly and others at high risk, which allows personal freedom while maintaining a lower risk of exposure even if infection rates rise due to waning use of social isolation.

\section{Compliance with Ethical Standards Statement}

Conflict of Interest There are no conflicts of interests.

Ethical Approval All relevant ethical standards were observed.

Human and Animal Rights No research involving human or animal participants was involved in the formation of this essay.

\section{References}

Agency France-Press. (2020, May 31). Coronavirus contract tracing; which counties are doing what. Gadgets 360. Retrieved July 22, 2020 from https:/gadgets.ndtv.com/apps/features/coronavirus-contact-tracingapps-which-countries-are-doing-what-2237952

Biomériex. (n.d.). bioMétirux receives emergency use authorization for BIOFIRE(r) COVID-19 test. Retrieved July 22, 2020 from https:/www.biomerieux.com/en/biomerieux-receives-emergency-useauthorization-biofirer-covid-19-test

Bremmer, I. (2020, June 12). The best global response to COVID-19 pandemic. Time. Retrieved July 22, 2020 from https://time.com/5851633/best-global-responses-covid-19/

Centers for Disease Control and Prevention. (2020). Considerations for Optimizing the Supply of Powered Air-Purifying Respirators (PAPRs). Retrieved July 22, 2020 from https://www.cdc. gov/coronavirus/2019-ncov/hcp/ppe-strategy/powered-air-purifying-respirators-strategy.html

Centers for Diseases Control and Prevention (CDC). (2020a). 10 leading causes of death by age group United States - 2020. [Online Resource]. Retrieved July 22, 2020 from https://www.cdc. gov/injury/wisqars/pdf/10LCID_All_Deaths_By_Age_Group_2010-a.pdf

Centers for Disease Control and Prevention. (2020b). Considerations for optimizing the supply of powered airpurifying respirators (PAPRs). Retrieved July 22, 2020 from https://www.cdc.gov/coronavirus/2019ncov/hcp/ppe-strategy/powered-air-purifying-respirators-strategy.html

Centers for Diseases Control and Prevention (CDC). (2020c, July 10)*. Daily updates of totals by week and state. [Online Resource]. Retrieved July 10, 2020 from https:/www.cdc.gov/nchs/nvss/vsrr/covid19 /index.htm *Online Resource updated regularly, hence date changes regularly.

Centers for Diseases Control and Prevention (CDC). (n.d.-a). Chronic diseases in America. [Online Resource]. Retrieved July 22, 2020 from https:/www.cdc.gov/chronicdisease/resources/infographic/chronicdiseases.htm

Centers for Diseases Control and Prevention (CDC). (n.d.-b) People who may be at increased risk for MERS. [Online Resource]. Retrieved July 22, 2020 from https://www.cdc.gov/coronavirus/mers/risk.html 
Chang, D. (2008, July). Traffic safety facts. National Highway Traffic Safety Administration. [Online Resource]. Retrieved July 22, 2020 from https://crashstats.nhtsa.dot.gov/Api/Public/ViewPublication/810853

Cilluffo, A. \& Cohn, D. (2019, April 11). 6 demographic trends shaping the U.S. and the world in 2019. Pew research center. [online resource]. Retrieved July 22, 2020 from https://data.worldbank.org/indicator/SP. POP.GROW?end=2018\&locations $=$ US\&start=2010

City of New York. (n.d.). COVID-19: data details on deaths [Online Resource]. Retrieved July 22, 2020 from https:www1.nyc.gov/site/doh/covid/covid-19-data-deaths.page

Clark, A., Flèche, S., Layard, R., Powdthavee, N., \& Ward, G. (2018). Origins of happiness. Princeton: Princeton University Press.

Dorn, A., Cooney, E., \& Sabin, M. (2020). COVID-19 exacerbating inequalities in the US. Lancet, 395(10232), 1243-1244. https://doi.org/10.1016/S0140-6736(20)30893-X.

Flaxman, S., et al. (2020). Estimating the effects of non-pharmaceutical interventions on COVID-19 in Europe. Nature., 584, 257-261. https://doi.org/10.1038/s41586-020-2405-7.

Ghaebi, M., Osali, A., Valizadeh, H., Roshangar, L, \& Ahmadi, M. (2020). Vaccine development and therapeutic design for 2019-nCoV/SARS-CoV-2: Challenges and chances. Journal of Clinical Psychology: 1-12. Doi: https://doi.org/10.1002/jcp.29771 [online resource]/.

Gibney, E. (2020, April 27). Whose coronavirus strategy worked best? Scientists hunt most effective policies. Nature. Retrieved July 22, 2020 from https://www.nature.com/articles/d41586-020-01248-1

Goodman, J. \& Rothfeld, M. (2020, April 23). 1 in 5 new Yorkers may have had Covid-19, antibody tests suggest. New York Times. Retrieved July 22, 2020 from https://www.nytimes.com/2020/04/23 /nyregion/coronavirus-antibodies-test-ny.html

Gowen, A., Hernandéz, A. \& Roza, L. (2020). Young people urged to take virus seriously as pandemic worsened in U.S. The Washington Post. Retrieved July 22, 2020 from https:/www.washingtonpost. $\mathrm{com} /$ national/young-people-are-driving-a-spike-in-coronavirus-infections-officials-say/2020/06/27 /3654638c-b7b4-11ea-a510-55bf26485c93_story.htm

Hsiang, S., Allen, D., Annan-Phan, S., Bell, K., Bolliger, I., Chong, T., Druckenmiller, H., Huang, L. Y., Hultgren, A., Krasovich, E., Lau, P., Lee, J., Rolf, E., Tseng, J., \& Wu, T. (2020, June 8). The effect of large-scale anti-contagion policies on the coronavirus (COVID-19) pandemic. Nature., 584, 262-267. https://doi.org/10.1038/s41586-020-2404-8.

Irfan, U. (2020). 2 new studies show shutdowns were astonishingly effective. VOX. [Online Resource]. Retrieved July 22, 2020 from https://www.vox.com/2020/6/9/21284087/coronavirus-covid-19-shutdownlockdown-cases-deaths

Joseph, A. (2020). Immunity to the coronavirus remains a mystery. Scientists are trying to crack the case. STAT https://doi.org/10.3201/eid2607.200282.

Kakodhar, P., Kaka, N., \& Baig, M. (2020). A comprehensive literature review on the clinical presentation, and Management of the Pandemic Coronavirus Disease 2019 (COVID-19). Cureus, 12(4), e7560. https://doi.org/10.7759/cureus.7560.

Kenny, S., McGrath, B., \& Phillips, R. (2017). The Routledge handbook of community development: Perspectives from around the globe. Abington: Routledge.

Li, D. (2020). New York City coronavirus death toll crosses 15,000 with probable cases. NBC news. Retrieved July 22, 2020 from https:/www.nbcnews.com/health/health-news/live-blog/2020-04-23coronavirus-news-n1190201/ncrd1191146\#blogHeader (note that article does not have a unique post. Scroll down to see the article.)

Mayo Clinic. (2020). Herd immunity and COVID-19 (coronavirus): What you need to know. [online resource]. Retrieved July 22, 2020from https://www.mayoclinic.org/diseases-conditions/coronavirus/indepth/herd-immunity-and-coronavirus/art-20486808

Mazzi, P. \& Robles, F. (2020 11). The costly toll of not shutting down spring break earlier. New York Times. Retrieved July 22, 2020 from https:/www.nytimes.com/2020/04/11/us/florida-spring-break-coronavirus. html

McNeil, D. (2018). Why don't we have vaccines against everything? The New York times. Retrieved July 22, 2020 from https://www.nytimes.com/2018/11/19/health/vaccines-poverty.html

Moore, R., Angela Lee, A., Hancock, J., Halley, M. \& Linos, E. (2020). Experience with social distancing early in the COVID-19 pandemic in the United States: implications for public health messaging. MedRxiv. doi: https://doi.org/10.1101/2020.04.08.20057067. Manuscript submitted for publication.

Musikanski, L., Phillips, R., \& Crowder, J. (2019). The happiness policy handbook, how to make happiness and well-being the purpose of your government. Gabriola Island, BC: New Society Publishers.

New York City Department of City Planning. (n.d.). Population - current and projected populations. [Online Resource]. Retrieved July 22, 2020 from https:/www1.nyc.gov/site/planning/planning-level/nycpopulation/current-future-populations.page 
Novotney, A. (2019). The risks of social isolation, American Psychological Association, 50 (5): 32 . Retrieved July 22, 2020 from https:/www.apa.org/monitor/2019/05/ce-corner-isolation

Phillips, R. (2015). Building community well-being across sectors with "for benefit" community business. In S. J. Lee, Y. Kim, \& R. Phillips (Eds.), Community well-being and community development, conceptions and applications (pp. 25-37). Dordrecht: Springer.

Phillips, R., \& Pittman, R. (2015). An introduction to community development (2nd ed.). London: Routledge.

Reger, M., Stanley, I. \& Joiner, T. (2020). Suicide mortality and coronavirus disease 2019-a perfect storm? JAMA Psychiatry, doi:https://doi.org/10.1001/jamapsychiatry.2020.1060 [online resource].

Sache, S., Lin, Y., Xu, C., Ramero-Severson, E., Hengartner, N., \& Ke, R. (2020). How contagiousness and rapid spread of severe acute respiratory syndrome coronavirus 2. Emerging Infectious Diseases, 26(7), 1470-1477. https://doi.org/10.3201/eid2607.200282.

Sample, I. (2020). Why we might not get a coronavirus vaccine. The Guardian. Retrieved July 22, 2020 from https://www.theguardian.com/world/2020/may/22/why-we-might-not-get-a-coronavirus-vaccine

Servick, K. (2020). COVID-19 contact tracing apps are coming to a phone near you. How will we know whether they work? Science Mag. Retrieved July 22, 2020 from https://www.sciencemag.org/news/2020 /05/countries-around-world-are-rolling-out-contact-tracing-apps-contain-coronavirus-how

Suicide Prevention Resource. (n.d.). Suicide by age. [Online Resource]. Retrieved July 22, 2020 from https://www.sprc.org/scope/age

The World Bank. (2020). Population growth (annual \%) - United States. [Online Resource]. Retrieved July 22, 2020 from https://data.worldbank.org/indicator/SP.POP.GROW?end=2018\&locations=US\&start=2010

Torres, E. (2020). The unthinkable toll in 2 NY funeral homes under the coronavirus pandemic. ABC news. Retrieved July 22, 2020 from https://abcnews.go.com/US/unprecedented-dead-pile-funeral-homes-feelcrush-coronavirus/story?id=70305788

United Nations. (2020). US must improve COVID-19 strategy to keep tens of millions from falling into poverty, urges rights expert. UN news. Retrieved July 22, 2020 from https://news.un.org/en/story/2020/04 $/ 1061982$

United States (US) Census Bureau. (2019). Age and sex composition in the United States 2019. [Online Resource]. Retrieved July 22, 2020 from https:/www.census.gov/data/tables/2019/demo/age-andsex/2019-age-sex-composition.html

United States Census Bureau. (n.d.-aa). QuickFacts New York city, New York. [online resource]. Retrieved July 22, 2020 from https://www.census.gov/quickfacts/newyorkcitynewyork

United States Census Bureau. (n.d.-b). QuickFacts United States. [online resource]. Retrieved July 22, 2020 from https://www.census.gov/quickfacts/usa

Verity, R., Okell, L., Dorigatti, I., Winskill, P., Whittaker, C., et al. (2020). Estimates of the severity of coronavirus disease 2019: A model-based analysis. The Lancet, 20(6), 669-677. https://doi.org/10.1016 /S1473-3099(20)30243-7.

Vitelli, R. (2020). Are we facing a post-COVID-19 suicide epidemic? Psychology today. Retrieved July 22, 2020 from https:/www.psychologytoday.com/us/blog/media-spotlight/202006/are-we-facing-post-covid19-suicide-epidemic

Witters, D. \& Agraway, S. (2020). 11 million at serious risk if infected with COVID-19. Gallup. Retrieved July 22, 2020 from https://news.gallup.com/poll/304643/million-severe-risk-infected-cov

World Health Organization. (2020). SARS (severe acute respiratory syndrome). [Online Resource]. Retrieved July 22, 2020 from https://www.who.int/ith/diseases/sars/en/

Wu, L., Wang, N., Chang, Y., Tian, X., Na, D., et al. (2007). Duration of antibody responses after severe acute respiratory syndrome. Emerging Infectious Diseases, 13(10), 1562-1564. https://doi.org/10.3201 /eid1310.070576.

Publisher's Note Springer Nature remains neutral with regard to jurisdictional claims in published maps and institutional affiliations. 


\section{Affiliations}

\section{Clinton Bliss $^{1} \cdot$ Laura Musikanski $^{2} \cdot$ Rhonda Phillips $^{3} \cdot$ Larry Davidson $^{4}$}

Clinton Bliss

drbliss@blissmedicalcenter.com

Rhonda Phillips

rphillips@purdue.edu

Larry Davidson

davidso@indiana.edu

1 Bliss Medical Center, Seattle, WA, USA

2 Happiness Alliance, Seattle, WA, USA

3 Purdue Honors College, West Lafayette, IN, USA

4 Indiana University, Bloomington, IN, USA 